\title{
GLOBALIZACIÓN, DERECHO PENAL MÍNIMO Y PRIVACIÓN DE LIBERTAD A 250 AÑOS DE LA OBRA CUMBRE DE BECCARIA*
}

\author{
Mayda Goite Pierre** \\ Arnel Medina Cuenca*** \\ Rodolfo Fernández Romo**** \\ Omar Huertas Díaz ${ }^{* * * * *}$ \\ Angie Lorena Ruiz Herrera*******
}

Fecha de recepción: 1 de septiembre de 2015

Fecha de evaluación: 22 de diciembre de 2015

Fecha de aprobación: 2 de marzo de 2016 Artículo de reflexión

DOI: http://dx.doi.org/10.18359/prole.1973

Forma de citación: Goite, M., Medina, A., Fernández, R., Huertas, O. \& Ruiz, A. (2016). Globalización, derecho penal mínimo y privación de la libertad a 250 años de la obra cumbre de Beccaria. Revista Prolegómenos Derechos y Valores, 19, 38, 109-126. DOI: http://dx.doi.org/10.18359/prole.1973

\section{Resumen}

El avance logrado en materia de garantías de los derechos de los individuos luego de los postulados de Cesare Beccaria, actualmente está siendo amenazado por el fenómeno de la globalización; este no solo permite el auge de la economía mundial, sino también un mayor desequilibrio social desembocando en la internacionalización y aumento de la delincuencia. Ante tal panorama, los diferentes países han optado por la implementación de un derecho penal del

\footnotetext{
El presente artículo es resultado del proyecto de investigación desarrollado por el Departamento de Ciencias Penales y Criminológicas de la Facultad de Derecho de la Universidad de La Habana (La Habana, Cuba) sobre el perfeccionamiento del sistema jurídico penal. Contó con la colaboración de la Sociedad Cubana de Ciencias Penales y del Grupo de Investigación "Escuela de Derecho Penal Nullum Crimen Sine Lege UN", reconocido y clasificado en categoría A Colciencias-2015 Universidad Nacional de Colombia (Bogotá, Colombia), COL0078909, dentro del proyecto de investigación "Perspectiva criminológica del sistema penitenciario y carcelario", ejecutado dentro de la Convocatoria 31 de 2014 "Apoyo a la creación, consolidación y fortalecimiento de los grupos de investigación de la Facultad de Derecho, Ciencias Políticas y Sociales de la Universidad Nacional de Colombia".

*** Profesora titular de Derecho Penal y decana de la Facultad de Derecho de la Universidad de La Habana (La Habana, Cuba). Presidenta de la Sociedad Cubana de Ciencias Penales. Correo electrónico: mayda@lex.uh.cu

*** Profesor titular de Derecho Penal de la Facultad de Derecho de la Universidad de La Habana (La Habana, Cuba). Vicepresidente de la Sociedad Cubana de Ciencias Penales. Correo electrónico: arnel@lex.uh.cu

**** Profesor titular de Derecho Procesal y Criminalística. Director del Departamento de Ciencias Penales y Criminológicas de la Facultad de Derecho de la Universidad de La Habana (La Habana, Cuba). Correo electrónico: rodolfo@lex.uh.cu

******A Abogado, profesor asociado, especialista en Derecho Penal y candidato a doctor en Derecho, Universidad Nacional de Colombia (Bogotá, Colombia). Ph.D. en Ciencias de la Educación, Universidad Simón Bolívar (Barraquilla, Colombia). Magíster en Derecho Penal Universidad Libre (Bogotá, Colombia). Máster en Derechos Humanos, Estado de Derecho y Democracia en Iberoamérica de la Universidad de Alcalá (Madrid, España). Magíster en Educación de la Universidad Pedagógica Nacional (Bogotá, Colombia). Socio de la Fundación Internacional de Ciencias Penales. Miembro de honor de la Fundación de Victimología. Miembro honorario de la Asociación Colombiana de Criminología. Correo electrónico: ohuertasd@unal.edu.co

******** Estudiante de Psicología e integrante del Grupo de Investigación "Escuela de Derecho Penal Nullum Crimen Sine Lege UN", reconocido y clasificado en categoría A Colciencias-2015, Universidad Nacional de Colombia (Bogotá, Colombia), COL0078909. Correo electrónico: alruizh@unal.edu.co
} 
enemigo, caracterizado por la imposición de nuevas tipicidades delictivas, el aumento de penas y la disminución de las garantías procesales en aras de la garantía de la seguridad ciudadana. No obstante, tal aplicación indiscriminada del derecho penal ha resultado en la intensificación de la violencia así como en una delincuencia ultraviolenta, influyendo en el fracaso del sistema penitenciario y en el detrimento de las medidas de prevención del fenómeno criminal.

\title{
Palabras clave:
}

Globalización, derecho penal, derecho penal mínimo, derecho penal del enemigo, delincuencia, privación de la libertad, prevención.

\section{GLOBALIZATION, MINIMUM CRIMINAL LAW AND DEPRIVATION OF LIBERTY 250 YEARS AFTER THE SUMMIT WORK OF BECCARIA}

\begin{abstract}
Summary
The progress achieved in terms of guarantees of the rights of individuals following the tenets of Cesare Beccaria, is currently being threatened by the phenomenon of globalization; this not only allows the growth of the world economy, but also a greater social imbalance leading to the internationalization and increase in crime. Before such background, different countries have opted for the implementation of a criminal law of the enemy, characterized by the imposition of new criminal profiles, the penalty increases and the decrease of procedural safeguards favoring the guarantee of the citizen security. However, such indiscriminate application of the criminal law has resulted in the escalation of violence and an ultra-violent crime, influencing the failure of the prison system and the detriment of the measures of prevention of the criminal phenomenon.
\end{abstract}

\section{Keywords:}

Globalization, criminal law, minimum criminal law, criminal law of the enemy, crime, deprivation of liberty, prevention.

\section{GLOBALIZAÇÃO, DIREITO PENAL MÍNIMO E PRIVAÇÃo DE LIBERDADE APÓS 250 ANOS DA OBRA-PRIMA DE BECCARIA}

\begin{abstract}
Resumo
O avanço alcançado em matéria de garantias dos direitos dos indivíduos após os postulados de Cesare Beccaria está sendo ameaçado atualmente pelo fenômeno da globalização; isto não apenas permite o auge da economia mundial, mas também um maior desequilíbrio social desembocando na internacionalização e aumento da delinquência. Diante de tal panorama, os diferentes países optaram pela implantação de um direito penal do inimigo, caracterizado pela imposição de novas tipicidades delitivas, o aumento de penas e a diminuição das garantias processuais em prol da garantia da segurança cidadã. Porém, tal aplicação indiscriminada do direito penal tem resultado na intensificação da violência, bem como em uma delinquência ultraviolenta, influenciando no fracasso do sistema penitenciário e no detrimento das medidas de prevenção do fenômeno criminal.
\end{abstract}

\section{Palavras-chave:}

Globalização, direito penal, direito penal mínimo, direito penal do inimigo, delinquência, privação de liberdade, prevenção. 
La prisión es una pena que por necesidad debe, a diferencia de las demás, preceder a la declaración del delito; pero este carácter distintivo suyo no le quita el otro esencial, esto es, que solo la ley determine los casos en que el hombre es digno de esta pena Bonesana (1993, p. 134).

\section{Introducción}

El derecho de castigar del Estado o ius puniendi, es la facultad que tiene el Estado para utilizar el poder punitivo e imponer penas o medidas de seguridad. Se trata de una reacción del aparato estatal en nombre de la sociedad, que tiene el deber constitucional de proteger a los demás ciudadanos de las acciones humanas más intolerables, empleando el poder punitivo para enfrentar los actos que atentan contra el llamado orden social.

Coincidimos con Olivares (1992) en que si bien la incidencia del derecho penal en la vida social es alta, no lo es hasta el punto de cincelar y sostener la sociedad; sino solamente, y eso no es poco, un instrumento jurídico que los que tienen atribuida la representación de la sociedad en lo legislativo y en lo judicial, aplican a aquellos que contravienen sus reglas. De la actitud que cada sistema penal positivo adopte, a través de las leyes penales de cada país, dependerá el mejor o peor juicio que se emita sobre dicho sistema.

Le corresponde a las constituciones nacionales de los Estados precisar los valores fundamentales de cada sociedad y a las normas de desarrollo, y a otras leyes del ordenamiento jurídico determinar, por una parte, los derechos que van a recibir protección del derecho penal y por la otra, el sistema de principios reguladores del actuar de los legisladores en su labor de instituir delitos y penas y de los jueces y tribunales a la hora de aplicarlas a los que los cometen.

Para Zaffaroni (2011) el poder punitivo, como todo ejercicio de coerción estatal que no persigue la reparación (no pertenece al derecho civil o privado en general), ni tampoco contiene o interrumpe un proceso lesivo en curso o inminente (coerción directa del derecho administrativo) precisa distinguir entre la legislación penal, que la hace el legislador, el poder punitivo que lo hacen las agencias ejecutivas y el derecho penal, que lo elaboran los profesores y doctrinarios. Lo clasifica en manifiesto cuando se habilita como tal en las leyes penales, como ocurre con el Código Penal y las leyes penales especiales y en latente, cuando se oculta en otras formas jurídicas, como la institucionalización psiquiátrica de personas mayores, de niños y adolescentes, lo que exige el control de los jueces, para que se adopte de forma manifiesta o para hacerlo cesar ${ }^{1}$.

El Estado va a ejercer esa facultad, a partir de la definición constitucional de los valores e intereses fundamentales de mayor relevancia, que reciben protección de la ley penal, mediante la determinación como delitos de las conductas que atentan contra ellos, "bien porque niegan los valores al destruirlos, bien porque su mera realización constituye un peligro indeseable" (Carbonell, 1995, p. 36), y de las consecuencias jurídicas derivadas de dichas conductas, las penas o medidas de seguridad.

El derecho penal debe reservarse para tutelar los valores o intereses con relevancia constitucional, los bienes jurídicos protegidos por la Constitución, que al recibir la protección de la ley penal, se convierten en bienes jurídicos penales.

El legislador al seleccionar las conductas humanas que reciben protección del derecho penal, debe circunscribirse al mínimo indispensable para garantizar los derechos de los ciudadanos sobre la base del principio general de que "las libertades de los ciudadanos terminan allí donde se afecta la libertad de todos los demás ciudadanos" (Olvera, 2013, p. 6), por lo que la potestad punitiva del Estado se limita a proteger solo a aquellos bienes jurídicos que teniendo relevancia constitucional, afectan a las libertades

\footnotetext{
1 La imagen dominante del poder punitivo la ejercen, en primer lugar los legisladores, que hacen la ley, luego los jueces que la aplican y en último lugar las agencias ejecutivas (policías), que cumplen las órdenes de los jueces.
} 
de los demás, y los que no alcancen esa connotación, deben ser considerados intrascendentes, para dichas libertades. El principio general de libertad, del que el de prohibición de exceso es un componente, viene a afirmar que tan solo puede restringirse la libertad de los ciudadanos en aras de la tutela de las propias libertades de los demás ciudadanos. Y solo en la medida de lo estrictamente necesario (Carbonell, 2001).

Desde los años noventa del pasado siglo y especialmente a partir de los acontecimientos del once de septiembre de 2001, con el derribo de las Torres Gemelas de Nueva York y otros hechos siguientes en Europa y Asia, con el pretexto de combatir el terrorismo y la delincuencia organiza$\mathrm{da}$, la tendencia ha sido a incrementar la cuantía de la pena y a endurecer las condiciones de reclusión, mientras que las modernas corrientes del pensamiento criminológico sobre la ineficacia del encierro como pena, quedaron en el olvido.

Los altos niveles de violencia y las grandes dosis de dolor que provocan la aplicación indiscriminada de las penas privativas de libertad -sobre todo en los países menos desarrollados- y el encierro en lugares sin las condiciones mínimas indispensables para la vida humana -donde los derechos humanos parecen no regir, ni tampoco importar demasiado-, le dan la razón a Zaffaroni (1998) cuando sostiene que:

La cárcel es verdaderamente una máquina deteriorante que genera en el privado de libertad una patología específica de regresión [...] Se determina en estos sujetos un síndrome de prisionización o "cultura de la jaula", en la que la propuesta de resocialización es irrealizable, y por el contrario se revela, junto con la ideología del tratamiento, como un discurso encubridor del verdadero papel que juegan dentro de un sistema penal irracional e ilegítimo (p. 104).

En el escenario actual, a 250 años de la obra cumbre de Beccaria, resulta compleja la lucha por mantener un derecho penal mínimo y respetuoso de los derechos humanos, por el cumplimiento de los principios limitativos del ius puniendi o derecho de castigar del Estado, las alternativas a la privación de libertad, la intervención mínima, la proporcionalidad de la pena y la resocialización de los sancionados; en la tarea de darle continuidad a los avances que se habían logrado desde la segunda mitad del pasado siglo, cuando el tratamiento penal adoptó una amplia variedad de formas, que incluían la despenalización de las conductas de escasa peligrosidad social, una mayor racionalidad en la determinación de la cuantía de las penas y medidas sustitutivas de las sanciones privativas de libertad, entre otras acciones, encaminadas a lograr una política penal, en la que los propósitos enunciados desde la doctrina, sobre el cumplimiento del principio de humanidad de las penas, se tenían en cuenta, en mayor grado por los poderes legislativo y judicial.

La presente investigación muestra las raíces históricas de los principios limitativos del ius puniendi y su evolución en la denominada era de la globalización, en la que de la mano de la sociedad de riesgo y el expansionismo acelerado e injustificado del poder punitivo del Estado, se abren nuevas proyecciones que es preciso estudiar desde la ciencia del derecho penal y la criminología.

Todo este panorama nos lleva a plantearnos como problema de investigación, el siguiente: ¿qué elementos nos aporta la doctrina y la evolución del derecho penal en la era de la globalización y la sociedad de riesgo para el análisis de los factores que inciden en el expansionismo del poder punitivo? ¿Cómo estructurar una adecuada política de racionalidad, sin dejar de enfrentar la delincuencia organizada, que también se globaliza? Para desarrollar la investigación, nos propusimos como objetivo general la fundamentación criminológica de los elementos generales que caracterizan actualmente al poder punitivo del Estado, y la necesidad de priorizar la aplicación consecuente del principio de intervención mínima en el enfrentamiento al delito en general y a la criminalidad organizada en particular.

Desde una perspectiva cualitativa y mediante el método de análisis documental de fuentes 
primarias y secundarias, se abordará el impacto de la globalización en el derecho penal, el expansionismo, la influencia del derecho penal del enemigo en el endurecimiento de las condiciones de reclusión y la crisis de la resocialización de los privados de libertad; postulando el apremio de aplicar medidas preventivas, desde el Estado, con la participación de la sociedad civil y otros factores sociales, que prioricen las de inclusión de los marginados y contribuyan a disminuir, en la medida de lo posible, los excesos en la utilización del poder punitivo.

\section{A. Sociedad de riesgo, globalización y expansionismo penal}

La globalización no ha resuelto los problemas de las desigualdades sociales que tanta incidencia tienen en el aumento de la criminalidad, la violencia y la inseguridad ciudadana. El tráfico de drogas, armas, la trata de personas y otros males, que van de la mano de la delincuencia organizada, se ven influenciados por la concentración del capital en determinadas áreas, que al propio tiempo, contribuye al mantenimiento del subdesarrollo en otras menos favorecidas (Goite y Medina, 2015).

Al ampliar la brecha entre ricos y pobres se ahonda la conflictividad social, disminuyen las posibilidades de empleo y en general de la satisfacción de las necesidades de los habitantes de los territorios menos favorecidos por el desarrollo económico, provocando importantes incrementos de los flujos migratorios, además de otros flagelos como el terrorismo, el tráfico de drogas y armas y el lavado de activos, cuyo crecimiento significativo provoca que desde la política, la sociedad civil y la doctrina, aunque en mucha menor medida, suban de tono los llamados a sustituir las políticas racionales y de prevención en el tratamiento a la delincuencia, por la mano dura, con más cárceles, penas más altas y reducción de las garantías penales y procesales que con tanto esfuerzo se han consagrado, sobre todo en los últimos sesenta años en los principales instrumentos internacionales de protección de los derechos humanos y en las constituciones y las leyes.

En la era de la globalización y la sociedad de riesgo (Beck, 2002), se generalizó en el mundo (incluida Latinoamérica) una tendencia a un expansionismo acelerado del poder punitivo del Estado, como consecuencia de la aplicación de políticas de excesiva represión de la actividad delictiva que no distinguen entre los crímenes verdaderamente violentos e intolerables para la sociedad y aquellos, que por sus características y las causas que los generan, podrían tener un tratamiento menos represivo.

El tema de la violencia y la inseguridad ciudadana, muy mal tratado desde la política y el poder mediático, unido a la tendencia a copiar fórmulas de otras regiones, con particularidades y niveles de desarrollo diferentes, es el principal obstáculo para lograr una estrategia de enfrentamiento a la delincuencia coherente y en armonía con el desarrollo alcanzado por nuestros países.

Estamos de acuerdo con el profesor Zaffaroni (2015) en que frente a la horrorosa violencia en Latinoamérica, los avatares epistemológicos del norte no nos brindan ninguna explicación y menos aún, alguna solución. Ninguna de esas criminologías del norte nos permite enfrentar la letalidad violenta de nuestra región ${ }^{2}$.

Tenemos ante nuestros ojos un fenómeno de altísima violencia, como claro producto de la política internacional. No podemos en Latinoamérica seguir a la zaga del saber criminológico central, que ignoró el genocidio o la violencia mortal por acción u omisión estatal, porque tenemos un genocidio en marcha ante nuestra vista (Zaffaroni, 2015).

\footnotetext{
$2 \quad \mathrm{Al}$ respecto asegura también el autor que: "Ha llegado al momento de mirar al norte desde el sur. No se trata de ninguna elección arbitraria, ni de ninguna declaración de independencia científica nacionalista, sino que nos enfrentamos a una brutal realidad, a una acuciante necesidad, que son las muertes, la letalidad violenta que recorre nuestra región" (2015, p. 59).
} 
Este fenómeno se caracteriza por la creación constante de nuevas figuras delictivas, la promulgación de leyes especiales y principalmente, la elevación de las penas privativas de libertad y del rigor en las condiciones de reclusión, que lejos de reducir los niveles de la delincuencia, lo que ha logrado es acrecentar significativamente el hacinamiento en las prisiones ${ }^{3}$ y el grado de violencia y agresividad de la delincuencia (Carranza, 2012).

Según López Barja (1997) la sociedad de nuestros días es interactiva en todos sus sistemas, lo individual solo tiene cabida en ese entramado interconectado de tecnologías, factores sociales, económicos y políticos que marcan el rumbo y definen las posturas, entonces si la delincuencia es un factor será un componente más y estará sometida al mismo análisis del riesgo global, esa es la idea primigenia de un derecho penal para la sociedad de riesgo que estará obligado a buscar respuestas eficaces para este momento histórico. El derecho penal ha de estar a la altura de las circunstancias y proporcionar medios precisos $y$ que sean los adecuados desde esa visión de la sociedad de riesgo.

Todo esto obliga a precisar que esos riesgos parten de la comprensión de que las normas por sí solas no son suficientes para ofrecer seguridad y para ello se delimita el "origen y los efectos del riesgo" (Beck, 2002, p. 6) que tienen incidencia directa para determinar la línea de lo individual y lo colectivo en el derecho penal. El riesgo afiliándonos a Beck (2002) se debe a la suma de las acciones individuales de muchos sujetos,

3 El director del Instituto Latinoamericano de las Naciones Unidas para la Prevención del Delito y Tratamiento del Delincuente señala como causas de la superpoblación penitenciaria que impera en América Latina el acelerado crecimiento de las tasas de encierro, con el consiguiente aumento del número de presos y presas excediendo la capacidad instalada de las cárceles para alojarlos. Vemos dos cuadros que exhiben la evolución de las tasas de las poblaciones penitenciarias de los países de América Latina y el Caribe durante las dos últimas décadas (1992-2011), donde naciones como Brasil y El Salvador las triplicaron entre 1992 y 2011, Argentina, Colombia, Costa Rica, Chile, México, Perú y Uruguay las duplicaron, y de estos países, Argentina y Uruguay están muy próximos a triplicarlas. aquí tenemos un problema importante para el derecho penal, "la pluralidad de sujetos" y los "entes colectivos".

Para Berzosa y Martínez (2002) la globalización de los intercambios, el aumento de las inversiones directas de las multinacionales en el extranjero y la integración mundial de los mercados financieros, han llevado a la internacionalización económica y a la intensificación de los flujos socioeconómicos a través de todo el planeta, pero también a una polarización mundial entre ricos y pobres dentro del Estado y, aún más, entre Estados ricos y Estados pobres, constituyendo esto la base de la desigualdad que se ha acrecentado en la actualidad.

Esa es la razón de nuestra coincidencia con el pensamiento de Terradillos (2001) cuando señala que la globalización, lejos de constituir una palanca de ampliación de estrategias penales de aplicación igualitaria, consagra la desigualdad, sobre todo como efecto de procesos de desregulación cuya consecuencia fundamental es la impunidad del poderoso en entornos débiles.

Con respecto a Latinoamérica, donde las dictaduras fueron rebasadas por el ideario incluyente, donde algunas economías emergentes (verbigracia Brasil) son más sólidas que algunas europeas y donde Gobiernos de corte social abogan por el "buen vivir", sí hay riesgos comunes, a saber el medioambiente y la salud colectiva, pero los Estados occidentales miran hacia aquí, incluso con aires de emigración, entonces la confrontación al delito no puede ser la misma (Terradillos, 2001), y eso es un mensaje a atender.

Otros factores gravitan en Latinoamérica como consecuencia de la fase contemporánea de internacionalización del capitalismo que corresponde a la globalización neoliberal, propiciadora de las desigualdades económicas y sociales por deficientes manejos en la distribución de la renta, la propensión a la marginalidad, la exclusión social y la corrupción generalizada, entre otros, que se constituyen irremediablemente en agentes aceleradores de la criminalidad (Mejías, 2014). 
Según el Informe sobre desarrollo humano del Programa de las Naciones Unidas para el Desarrollo (2013) transcurridos los primeros trece años del nuevo siglo, en el análisis del fenómeno de la delincuencia, es necesario considerar también, que propiciado por la globalización, se está produciendo un reequilibrio impresionante del poder económico mundial ${ }^{4}$, lo que a mediano plazo incidirá en las tendencias del comportamiento del delito a escala global, pero sin olvidar las particularidades de los países de nuestra región que no son las mismas. Por primera vez en 150 años, la producción combinada de las tres economías líderes del mundo en desarrollo -Brasil, China e India- es prácticamente igual al PIB combinado de las potencias industriales más sólidas del norte: Canadá, Francia, Alemania, Italia, Reino Unido y Estados Unidos ${ }^{5}$.

En consecuencia, es menester adaptar el sistema penal a la autonomía lograda por la economía en relación con la política; con el surgimiento de nuevas estructuras de decisión en el ámbito

$4 \quad$ En el referido informe se afirma que en tiempos de incertidumbre, los países del sur están sosteniendo colectivamente el crecimiento económico mundial, apuntalando a otras economías en desarrollo y reduciendo la pobreza. Aún les quedan grandes desafíos por afrontar, y en ellos vive gran parte de la población pobre del mundo. No obstante son un ejemplo de que con políticas pragmáticas y un claro enfoque del desarrollo humano pueden surgir oportunidades latentes en sus economías, estimuladas por la globalización. Las regiones en desarrollo también han estrechado vínculos entre sí: entre 1980 y 2011 el comercio entre países del sur aumentó de menos del $8 \%$ del comercio internacional de mercancías a más del $26 \%$. Se puede decir que existe un "sur" en el norte y un "norte" en el sur, las élites, tanto del norte como del sur, están cada vez más globalizadas y conectadas, se benefician con la enorme generación de riqueza alcanzada en la última década, en parte debido a una aceleración de la globalización.

5 En 1950, Brasil, China e India juntos representaban solo el $10 \%$ de la economía mundial, mientras que a los seis líderes económicos tradicionales del norte les correspondía más de la mitad. Según las proyecciones de este informe, para el año 2050 Brasil, China e India juntos serán responsables del $40 \%$ de la producción mundial, superando ampliamente la producción combinada proyectada del bloque actual del Grupo de los Siete. En el presente, al sur en su totalidad le corresponde alrededor de la mitad de la producción económica mundial, mientras que en 1990 producía solo un tercio. planetario; con las alteraciones sufridas por las empresas, sectores, regiones, países y continentes en materia de competitividad. Así mismo, se vincula con la "desnacionalización" de los derechos, la "desterritorialización" de las formas institucionales y la descentralización de las estructuras políticas del capitalismo; la estandarización de las prácticas comerciales en el ámbito mundial, la desregulación de los mercados de capitales, la interconexión de los sistemas financiero y de seguridad a escala global, la reasignación geográfica de las inversiones productivas y la volatilidad de las transacciones especulativas, entre otros escenarios, como el vertiginoso desarrollo de las comunicaciones, la proliferación de los movimientos migratorios y los cambios radicales en la división internacional del trabajo; o a la estructura político-económica multipolar, en que se desarrolla la sociedad del siglo XXI (Velásquez, s. f.).

La globalización con sus riesgos y contradicciones nos muestra el dilema de un derecho penal máximo y un derecho penal mínimo, que encamina a la legislación penal hacia una de las dos posiciones, o nos aferramos a continuar apegados al derecho penal clásico o buscamos fórmulas compatibles con los principios y garantías penales y procesales, que nos permitan enfrentar la transnacionalización de la delincuencia, cada vez más globalizada, en las nuevas condiciones, en un mundo en el que las grandes compañías transnacionales y los bloques económicos se proyectan como sustitutos del Estado en la conducción de los destinos de la humanidad.

Zaffaroni, Alagia y Slokar $(2006)^{6}$ han manifestado al analizar las funciones del derecho

\footnotetext{
$6 \quad$ Zaffaroni no desconoce los aportes importantes de los distintos momentos de la evolución de la teoría del delito. Por ello asegura: (i) el esquema de Liszt tuvo la virtud de oponer el derecho penal al poder punitivo, (ii) el sistema Liszt-Beling fijó las cuatro categorías sobre las que se discutiría a lo largo del siglo siguiente la teoría de delito, (iii) el neokantismo significó un duro entrenamiento para la fina construcción sistemática, (iv) el finalismo aportó su toque de atención en cuanto al respeto por el mundo y sus datos, y (v) el funcionalismo confiesa con singular sinceridad que los conceptos jurídico-penales son políticamente funcionales.
} 
penal, que el vínculo que establece un derecho penal reductor con las ciencias sociales debe ser de preferencia a través del marco de una sociedad entendida conforme con una teoría del conflicto. Es decir, una sociedad integrada por grupos cuyos intereses no coinciden sino que colisionan y compiten, lo que da lugar a un proceso de cambio continuo. En este marco el poder punitivo no tiene signo positivo, porque interviene en la conflictividad social siempre del lado del más fuerte, tal como se certifica con toda la historia del poder punitivo.

Por lo tanto, el derecho penal liberal concebido en el mismo contexto no puede legitimarlo en ninguna medida considerable, sino reducirlo y contenerlo. El derecho penal liberal no debe sostenerse solo porque sea saludable para un sistema social, sino porque el poder punitivo tiende a reprimir el conflicto mismo y frena la dinámica social que pugna por ampliar los ámbitos de autorrealización de las personas (Zaffaroni et al., 2006).

La búsqueda de alternativas para garantizar la seguridad de los ciudadanos desde el Estado y también desde otros actores de la sociedad, como los partidos políticos, los movimientos sociales, la empresa privada y otros mecanismos de control social, no es nueva. En el artículo 2 de la Declaración de los Derechos del Hombre y del Ciudadano de 1789, se afirma que: "El objeto de toda sociedad política es la conservación de los derechos naturales e imprescriptibles del hombre. Estos derechos son la libertad, la propiedad, la seguridad y la resistencia a la opresión [...]".

Determinar cuáles son los nuevos intereses que requieren protección en las actuales circunstancias y la forma en que serán protegidos con el poder punitivo del Estado, se torna un ejercicio muy complejo que se va a interpretar de acuerdo con los programas de los partidos políticos y las presiones de la empresa privada y la sociedad civil.

Desde los medios de comunicación, que por lo general responden a los mencionados intereses, se responsabiliza a los códigos penales y las leyes procesales que surgieron de las profundas reformas que se realizaron en nuestra región, desde la última década del pasado siglo, con la violencia, la inseguridad ciudadana y otros males sociales y las medidas adoptadas para reducir los niveles de prisión provisional y la cuantía de las penas privativas de libertad, pasan de la letra de la ley a ser objeto de críticas en los programas de Gobierno de los candidatos presidenciales y también de los aspirantes a diputados, senadores, alcaldes, concejales y otros cargos públicos a los que se accede por elección popular.

Con los nuevos Gobiernos se inicia un proceso paulatino de desmontaje de las garantías penales y procesales que con tanto esfuerzo se han construido con la contribución de numerosos hombres y mujeres de buena voluntad.

La globalización neoliberal ha extendido la concepción estadounidense de intolerancia penal, populismo punitivo, de los modelos penales del broken windows y zero tolerance que conducen a un agravamiento de las penas y a una extensión de la calificación de conductas delictivas a comportamientos que antes no lo eran. A ello habría que añadir el "relajamiento" del garantismo penal en aras de una pretendida eficacia jurídica. Consecuencia lógica de lo anterior es que se incremente el número de delincuentes manteniéndose constantes los comportamientos. $\mathrm{Si}$ se agrega una variable socioeconómica, el abandono de las políticas sociales de redistribución y asistencia, que han tenido y tienen el efecto de incrementar las desigualdades económicas y sociales, se genera todo un caldo de cultivo para comportamientos considerados delictivos (Lara, 2013) ${ }^{7}$.

El llamado populismo punitivo, frase acuñada entre otros autores por Lara y León, en nuestro contexto latinoamericano entendemos su concepto, dimensión $y$ alcance en los estudios de Zaffaroni en su obra $\mathrm{La}$ cuestión criminal cuando hace referencia a la criminología mediática. Otro de los temas relevantes para entender el populismo punitivo, precisan los autores, es el contexto bélico que ha inundado el imaginario político-social y la realidad posterior al 11/S. El gran despliegue de una retórica sobre la guerra en un mundo globalizado ha llevado a la persecución de métodos de control social 
A la par, el proceso de globalización económica en el que vivimos, es un vehículo idóneo para el desarrollo de la delincuencia transnacional, que mantiene su centro de operaciones en países que por su inestabilidad estatal lo permiten, extendiendo sus actividades a gran parte del globo terráqueo. De ahí, la existencia de una nueva forma de delincuencia sin fronteras (Lara, 2013) ${ }^{8}$.

Si observamos con detenimiento el papel desempeñado por las Naciones Unidas y otros organismos regionales como la Organización de Estados Americanos, se aprecia que en los últimos años el énfasis de su actividad, se ha ido desplazando de la aprobación de numerosos instrumentos jurídicos internacionales en defensa de los derechos humanos, a los relacionados con la lucha contra la droga, el terrorismo, la delincuencia organizada transnacional y otros, que evidencian la preocupación de la comunidad internacional por los problemas asociados con la globalización de la delincuencia que ha evolucionado desde una delincuencia organizada regional, pasando por el crimen organizado de índole nacional, convirtiéndose a la postre en transnacional, hasta llegar a nuestros días, en los que se habla incluso de alianzas estratégicas (De la Cruz, 2005).

internacionales e intranacionales, donde estas dos dimensiones tienden a confundirse. En un mundo globalizado, con la soberanía puesta en cuestión estaríamos pasando de un mundo westfaliano, de la guerra entre Estados a uno poswestfaliano donde las guerras serían guerras civiles, en un estado de guerra perpetua.

$8 \mathrm{Al}$ respecto analiza que tomando en consideración el producto del tráfico de drogas, las ventas ilícitas de armas, el contrabando de materiales nucleares o las ganancias de actividades controladas por las mafias (prostitución, juego, mercado negro, divisas), Naciones Unidas ha denunciado que los ingresos mundiales anuales de las organizaciones criminales transnacionales equivalen al producto nacional bruto (PNB) de los países de ingreso débil (según la categorización de la banca mundial) y de sus tres mil millones de habitantes. Así, mientras los mercados financieros despliegan una actividad febril y sin cortapisas, inmersos en un capitalismo "de casino", por completo desligado de los procesos productivos, zonas enteras asisten a la pérdida de su autonomía política y jurídica, así como al desgarramiento de sus estructuras sociales y productivas, con un futuro muy difícil a considerar (Pisarello, 2001).
En realidad, los delincuentes aprovechan ahora el proceso de globalización de la economía mundial, transfiriendo sus fondos rápidamente por las fronteras internacionales. El vertiginoso desarrollo de la información financiera, la tecnología y las comunicaciones viabilizan el manejo del dinero para entrar en el mundo de los negocios en cualquier parte con velocidad y facilidad; y así, como la génesis del problema lo encontramos en la globalización, la respuesta que las legislaciones han adoptado para su combate, también se da en un contexto globalizado (De la Cruz, 2005). En ese orden de ideas, Silva (1999) pronostica lo siguiente:

[...] el derecho penal de la globalización y de la integración supranacional, será un derecho desde luego crecientemente unificado, pero también menos garantista, en el que se flexibilizarán las reglas de imputación, y en el que se relativizarán las garantías político-criminales, sustantivas y procesales (pp. 63-64).

\section{B. Las penas privativas de libertad y el derecho penal mínimo}

El origen del principio de intervención mínima coincide con el nacimiento del liberalismo, que es una doctrina política que surgió en la segunda mitad del siglo XVIII, principalmente en Francia y Reino Unido (Milanese, s. f.), caracterizada por la "reivindicación de un importante espacio de libertad en el ámbito personal, religioso, literario, económico, etc.; un espacio mucho más amplio de lo que los filósofos del pasado (aun los más ilustrados, como Spinoza o Locke) consideraban razonable" (Vergara, 1999, citado en Milanese, s. f.).

El Estado a través del derecho es el único ente que tiene la facultad de determinar qué conductas son prohibitivas dentro de la sociedad y qué pena deberá imponerse cuando no se respete la norma jurídica limitativa. El Estado deberá acordar los bienes a ser protegidos mediante el 
derecho penal, en uso de su potestad punitiva, un poder coercitivo que no es absoluto y que tiene sus limitaciones, toda vez que este poder público que posee el Estado debe cumplir los principios limitativos del derecho de castigar o ius puniendi, que se integra, entre otros, por los principios de legalidad, intervención mínima o prohibición de exceso, proporcionalidad, humanidad y resocialización.

La doctrina ha desarrollado como principios que hoy alcanzan rango constitucional, los de legalidad, culpabilidad, humanidad, proporcionalidad, intervención mínima, igualdad, resocialización, presunción de inocencia y otros que se erigen como escudos protectores del individuo frente al poder del Estado (Milanese, s. f.).

Desde los últimos años de la pasada centuria y en lo que va del siglo XXI, los principios limitativos del ius puniendi se entienden de manera diferente desde la política, los instrumentos jurídicos internacionales y numerosas legislaciones nacionales en las que la influencia del derecho penal del enemigo y las tendencias expansionistas imperantes, ejercen un impacto negativo en las aspiraciones de poder contar con un derecho penal garantista y respetuoso de los derechos humanos, lo que en materia penitenciaria se asocia a sanciones más altas y elevación de los requisitos para el otorgamiento de la libertad anticipada y otros beneficios penitenciarios (Carranza, 2012).

$\mathrm{Al}$ analizar las tendencias vigentes del derecho penal, Morillas expresó en 2013 que la tendencia legislativa no solo en España sino en casi todo el derecho comparado camina hacia presupuestos de expansión que, en ocasiones, resultan sumamente discutibles cuando no sorprendentes para una moderna y legitimada en parámetros democráticos y sociales ciencia punitiva.

El aval doctrinal que dan ciertas concepciones dogmáticas, entre las que destaca el funcionalismo radical, y su brazo ejecutor, el derecho penal del enemigo, a dichas apetencias expansionistas fortalece las formas organizadas de poder, esto es los Estados, el desarrollo de sus inclinaciones represivas por lo general disimuladas en invocaciones a la seguridad de los ciudadanos en lo que lo útil, lo funcional, parece hacer retroceder los niveles del imprescindible garantismo penal y aboca, cada vez con mayor frecuencia, a una utilización indiscriminada del derecho punitivo y al continuado uso de la pena de prisión (Morillas, 2013).

En definitiva, reducir la presencia de la pena de prisión y su aplicación para racionalizar, todavía con más intensidad, las políticas de justicia penal sobre el indispensable soporte del respeto a los derechos humanos de todos los ciudadanos incluidos los condenados, las exigencias de justicia social sobre la trilogía garantista y aseguradora: delincuente-sociedad-víctima. Únicamente así se podrá legitimar en cierta medida la pena de prisión en el Estado social y democrático de derecho (Morillas, 2014).

\section{La influencia del derecho penal del enemigo en el endurecimiento de las condiciones de reclusión}

Para combatir a los traficantes de armas, drogas y seres humanos, que junto al terrorismo, la corrupción y otros males se encuentran en el núcleo de la preocupación de los Gobiernos, los partidos y la sociedad civil, un sector de la doctrina penal y criminológica considera necesaria la promulgación de normas penales de mayor severidad, con la inclusión de nuevos delitos y un sistema de justicia penal que coloque en el centro de su actividad la defensa de la sociedad, en detrimento de las garantías penales y procesales, por las que la humanidad ha luchado durante siglos y que cuentan con reconocimiento universal.

Coincidimos con el juez y profesor de la Universidad de Buenos Aires, Luis Niño (2015), en que las construcciones teóricas orientadas a la consideración de determinados individuos de la especie humana como seres diferentes a la generalidad, extraños a la comunidad, anormales, peligrosos o enemigos, con la paralela 
disminución o cancelación del reconocimiento de su personalidad, como paso previo a su eliminación o su exclusión del medio social, distan de ser novedad.

Platón dedicó diversos pasajes de su República y los cuatro últimos libros de su obra más extensa - Las leyes- a la cuestión del delito. Si bien partía de valorar a quien lo comete como un individuo incapacitado para acceder al plano de las ideas puras, se esmeró en aconsejar la eliminación lisa y llana de aquellos cuya deficiencia en tal materia no fuera posible de enmienda (Niño, 2015).

Por otra parte, no se trata de problemas nuevos, son fenómenos, que de la mano de la globalización se han complejizado en extremo, porque como afirma Rivero (s. f.), en principio se debe aseverar que el nacimiento del crimen organizado no se puede fijar históricamente en una fecha y lugar determinados, sino más bien, deriva de varios acontecimientos políticos, económicos, sociales y culturales, que han evolucionado de forma paulatina y que en el presente se siguen desarrollando, sin que exista un freno aparente del fenómeno, el cual abarca diversos puntos geográficos.

Con la expansión del capitalismo, paralelamente se extiende la delincuencia, sobre todo en países que tienen instituciones mermadas y en donde falta autoridad o hay desconfianza en ella; lo que genera un caldo de cultivo idóneo para que el fenómeno se acreciente. Así, el delito opera primeramente, de manera local y va esparciendo sus redes de organización territorial, hasta conformar modelos sofisticados de organización regional, escalando el ámbito nacional y trascendiendo las fronteras (Rivero, s. f.).

El principal exponente de la teoría del derecho penal del enemigo, es el jurista alemán Günther Jakobs (2006), quien distingue dos regulaciones del derecho penal, dos modos de proceder con los delincuentes: el trato con el "ciudadano", en el que se espera a que cometa el delito para reaccionar, viéndole como persona que ha infringido el pacto, pero que no persiste en ello, manteniendo el estatus de persona; y el trato con el "enemigo", que se desvía del pacto por principio, perdiendo la consideración normativa de persona, y que por ello debe ser interceptado y combatido antes por su peligrosidad, una custodia de seguridad anticipada que se denomina "pena", por tratarse de individuos que hay que coaccionar para evitar que destruyan el ordenamiento jurídico.

El derecho penal del enemigo se convierte en un derecho de guerra, un nuevo formato que configura una legislación penal y procesal preventiva que solo atiende a la eliminación del riesgo generado por el "individuo peligroso" a través de medidas de seguridad (Portilla, 2005). Porque la finalidad última no es sino una: la conservación de los intereses del sistema, la capacidad funcional de sus órganos y la defensa del Estado (Portilla, 2005). Porque todo vale en la guerra contra los enemigos. Enemigos que si son terroristas son aún más enemigos, y las justificaciones llegan todavía más lejos (Sanz, 2012).

Tal como se encuentra concebido el derecho penal del enemigo, resulta lógico que la suspensión de garantías penales y procesales viniera a formar parte esencial de esta misma estrategia, en el entendido de que con el catálogo de derechos que la normativa democrática atribuye tradicionalmente a todo ciudadano en pie de igualdad, posiblemente no resultaría tan fácil alcanzar el objetivo propuesto, lo que supondría, por consiguiente, el fracaso del sistema9 .

Se trata, como se ve, de una concepción que alienta la "permeabilidad" entre la legislación de emergencia y la ordinaria, en virtud de la cual las normas dispuestas para el delincuente-enemigo han acabado formando parte del derecho concebido para el resto de los delincuentes (Cervini, s. f.). El propio Jakobs (2003) se permite la sutileza

9 Sobre los antecedentes y evolución de la teoría del derecho penal del enemigo, desde Platón y Aristóteles, hasta Thomas Hobbes, el precursor del despotismo ilustrado, Johann Gottlieb Fichte y Carl Schmitt, entre otros de sus más destacados defensores, hasta Günther Jakobs. 
de advertir que "un derecho penal del enemigo claramente delimitado es menos peligroso desde la perspectiva del Estado de derecho, que entremezclar todo el derecho penal con fragmentos de regulaciones propias del derecho penal del enemigo" (p. 56).

Para Sanz (2012) existen dos diferencias entre el derecho penal y el derecho penal del enemigo, $y$ que cabe en consecuencia reprochársele a este último: (i) que no estabiliza normas (prevención general positiva) sino que demoniza (excluye) a ciertos grupos de infractores; y (ii) que es un claro derecho penal del autor.

El expansionismo del derecho penal reflejado especialmente en la multiplicación de tipos legales, el adelantamiento de la ilicitud a las etapas preparatorias, el aumento de penas y el endurecimiento de las condiciones de reclusión, se amalgaman con un derecho penal simbólico entroncado en el denominado realismo de derecha. Así, se apela a una normativa abstracta que busca tranquilizar a la opinión pública mediante producciones legislativas que de antemano son de imposible cumplimiento (Javier, 2012).

Sus delitos son cada vez más violentos, innecesariamente violentos, salvo para evitar identificaciones posteriores, como consecuencia de una política de castigo penitenciario desmesurado incluso para delitos mínimos, tiene como resultado una ampliación de la violencia en la sociedad y la aparición de una delincuencia ultraviolenta, lo que se traduce en un mayor hacinamiento carcelario y más presión sobre los Gobiernos desde la empresa privada y la sociedad, para buscar soluciones en la aplicación de las políticas privatizadoras, que desde las últimas décadas del pasado siglo vienen aplicando un número creciente de países desarrollados.

Estamos retornando al derecho penal de autor, a los tipos penales abiertos, a las medidas de seguridad, a un adelantamiento injustificado de la culpabilidad y otros males que ya parecían superados, como resultado de los esfuerzos de cientos de miles de hombres y mujeres de buena voluntad, que, como dijimos líneas arriba, en diferentes épocas han contribuido al reconocimiento universal de los derechos humanos fundamentales.

Los derechos fundamentales y el concepto de Estado de derecho constituyen una legitimación axiológica. Los derechos fundamentales concebidos como paradigma de legitimidad del derecho vigente y de la actuación de los poderes públicos deben entenderse con los caracteres tradicionalmente atribuidos a los derechos humanos, solo que están positivizados: igualdad, universalidad, indisponibilidad, atribución ex lege y rango constitucional, por ello están supraordenados en las normas jurídicas (Zaffaroni, 2001).

Por muy difícil que se presente la lucha contra el terrorismo internacional y el crimen organizado en la era de la globalización, las soluciones no podremos buscarlas en más delitos, aplicación indiscriminada de la prisión provisional, mayores penas y reglas más rigurosas para la excarcelación anticipada de los privados de libertad. Es evidente que ese no es el camino correcto, con el pretexto de combatir el terrorismo y la delincuencia organizada, no debemos recurrir a la utilización excesiva del derecho penal y al margen de los principios limitativos del ius puniendi, que han sido incorporados a las constituciones y las leyes, como resultado de un largo proceso de defensa de los derechos humanos.

En este escenario, resulta compleja la batalla por la disminución de la prisión provisional, las alternativas a la privación de libertad, la intervención mínima, la proporcionalidad de la pena y la resocialización de los sancionados, en la tarea de darle continuidad a los avances que se habían logrado desde la segunda mitad del pasado siglo, cuando el tratamiento penal adoptó una amplia variedad de formas, que incluían la despenalización de las conductas de escasa peligrosidad social, menor aplicación de la prisión preventiva, mayor racionalidad en la determinación de la cuantía de las penas y medidas sustitutivas de las penas privativas de libertad, entre otras acciones, dirigidas a lograr una política penal, en la que los 
propósitos enunciados desde la doctrina, sobre el cumplimiento del principio de humanidad de las penas, se tenían en cuenta, en mayor grado por los poderes legislativo y judicial.

Se trata de un tema que no podemos abandonar, al menos los que continuamos pensando que la solución a los problemas del incremento de la criminalidad hay que buscarla en las políticas de inclusión social y no en el aumento del rigor de las penas, ni en la construcción de más cárceles, porque como ha dicho con acierto el experto en sistemas penitenciarios de los Estados Unidos Robert Gangi: "Construir más prisiones para detener el delito es como construir más cementerios para detener las enfermedades mortales" (citado en Blaustein, 2006, p. 12).

Ante este panorama, se impone la necesidad de que, al mismo tiempo que se combate la delincuencia y sus manifestaciones ligadas al crimen organizado, respetando los derechos de los procesados y sancionados, que han sido consagrados en numerosos instrumentos jurídicos internacionales y en las constituciones y los códigos penales y procesales, se avance también en la investigación científica de manera que se puedan proyectar estrategias nacionales y locales que comprendan, entre otras, medidas de inclusión social y proyectos comunitarios que sitúen a la prevención del delito en el centro de su actividad.

La mira debemos enfocarla en el tipo de sociedad que necesitamos para que al menos las futuras generaciones, tengan la opción de vivir un clima de paz y armonía, en el que sin llegar a prescindir del derecho penal y de la utilización del poder punitivo del Estado, los niveles de violencia se tornen tolerables y los conflictos sociales más graves, puedan ser sustituidos por la solidaridad, la igualdad y la libertad, en armonía con un derecho punitivo verdadero protector de todos los derechos humanos, y una educación y compromiso entre los ciudadanos que hagan inviable la destrucción gratuita, aberrante e incomprensible de bienes jurídicos del más alto nivel, entre ellos la vida (Morillas, 2002).

\section{La crisis de la resocialización de los privados de libertad}

En correspondencia con el principio de resocialización, cuando se aplique la pena privativa de libertad es necesaria la ejecución de una política penitenciaria, que sitúe al sancionado en el centro de su contenido, adoptando las medidas imprescindibles para evitar la no socialización de los reclusos, facilitarles la comunicación con el exterior y siempre contando con su anuencia, propiciarles una adecuada preparación para su futura reincorporación a la vida en libertad, mediante la concesión de permisos de salida de los establecimientos penitenciarios por periodos cortos de tiempo y la aplicación de un tratamiento progresivo, que les facilite cambiar de régimen penitenciario y pasar a condiciones carcelarias de semilibertad y que hagan posible obtener la libertad condicional, en el menor tiempo posible, $y$ reincorporarse a la sociedad ${ }^{10}$.

Para Mir Puig (s. f.) el principio de resocialización debe entenderse en el sentido que hemos explicado aquí, y no, como sustitución coactiva de los valores del sujeto, ni como manipulación de su personalidad, sino como un intento de ampliar las posibilidades de participación en la vida social, una oferta de alternativas al comportamiento criminal.

El principio de resocialización se vincula al de humanidad en materia de ejecución penitenciaria, porque obliga a tratar a los reclusos con el debido respeto y a facilitar su resocialización y la reincorporación plena a la sociedad.

La crisis de las penas privativas de libertad aparece desde su nacimiento mismo, y coincidimos con Pavarini (1986) en que esta crisis será

10 No obstante, con preocupación se evidencia que los reclusos colombianos muestran niveles elevados de temores en lo relacionado con su futuro en libertad. Así, en la investigación realizada por Huertas, Bolívar, Sotelo, Camargo y López (2015) los principales temores de los internos consultados se centraron en la consecución de un empleo luego de regresar a la libertad, su vínculo con la comunidad y la ayuda económica desde sus familias. 
permanente. Al fracasar la idea retributiva de la pena se pasa al intento de darle un contenido útil. Se busca justificarla, sabiendo que desde su nacimiento es imposible hallarle tal justificación teniendo una finalidad real centrada en la "impartición de dolor" (Christie, 1988). Nadie puede establecer parámetros de valoración para una pena que puede ser aplicada desde un segundo hasta la eternidad. A esto debe agregarse que la pena muchas veces no es estudiada de manera que se separe aquella concepción de eternidad e inmutabilidad que se le otorga (Rodríguez, 2014).

A pesar de los grandes esfuerzos de la comunidad internacional y de los Estados por perfeccionar los sistemas penitenciarios, la realidad en la gran mayoría de los países es muy diferente, incluidos muchos de los desarrollados, como consecuencia de las cada vez más frecuentes crisis económicas, que afectan sensiblemente los presupuestos de los establecimientos penitenciarios, que son los que reciben al sancionado y están obligados por la ley a garantizarles un tratamiento resocializador, conducente a prepararlos para retornar a la vida en libertad.

Al respecto el periodista y escritor uruguayo Eduardo Galeano, en una conferencia pronunciada en el auditorio de la Facultad de Derecho de la Universidad de Costa Rica, el día 21 de junio de 1996, al referirse a la situación de los presos en América Latina expresó que "las dictaduras militares ya no están, pero las frágiles democracias latinoamericanas tienen cárceles hinchadas de presos. Los presos son pobres, como es natural".

Esta situación, con relativa frecuencia en los últimos años, lejos de mejorar tiende a agravarse por los efectos negativos de la globalización neoliberal y las políticas de ajustes estructurales que vienen obligadas a aplicar los Estados, conforme con las fórmulas del Fondo Monetario Internacional y del Banco Mundial, que con muy pocas excepciones, para nada favorecen las reformas penitenciarias, que con muchos esfuerzos han emprendido algunos Estados, pues los costos que ocasiona el sistema carcelario están precisamente enmarcados entre los que es necesario ajustar para disminuir el gasto público.

Hasta hace poco tiempo, como afirma Asencio (2006), la utopía penitenciaria era la resocialización del delincuente. Hoy en día, en cambio, abandonada toda idea resocializadora, la verdadera utopía penitenciaria es, sencillamente, que se cumplan las leyes.

Basta leer la mayoría, por no decir la totalidad, de las legislaciones penitenciarias de los países desarrollados o no y después visitar sus cárceles, para comprobar cómo en ninguno de ellos se cumple en su totalidad lo previsto en las normas. Las disposiciones penitenciarias, por lo general, viven alejadas de la realidad. La falta de voluntad política y la ignorancia de que el condenado es un sujeto de derechos -idea esta que aparece recientemente-, han propiciado el incumplimiento de las leyes penitenciarias (Asencio, 2006).

Ante estas situaciones no podemos aspirar a que se pueda conseguir el objetivo de que las personas al egresar de las cárceles vivan en libertad respetando la ley cuando, además del incumplimiento de las leyes penitenciarias, el paso entre la sociedad carcelaria y la sociedad libre se realiza de forma brusca. Es evidente que el interno que no ha tenido contacto con la sociedad libre, sufre un auténtico shock cuando abandona la cárcel y se encuentra en una sociedad en absoluto distinta a aquella que deja atrás y a la que seguramente volverá pronto (Asencio, 2006).

\section{A modo de conclusiones}

En la era de la globalización, al aumentar la brecha entre ricos y pobres se incrementa la conflictividad social, disminuyen las posibilidades de empleo y en general de la satisfacción de las necesidades de los habitantes de los territorios menos favorecidos por el desarrollo económico, creando un acrecentamiento significativo de los niveles de violencia e inseguridad ciudadana, que es necesario enfrentar, aplicando medidas preventivas, desde el Estado, con la participación de la sociedad civil y otros factores sociales, priorizando 
la inclusión social de los excluidos de siempre y de los que se les han ido incorporando como resultado de las frecuentes crisis económicas.

Las políticas de mano dura contra la delincuencia no constituyen la vía idónea para enfrentar la violencia y la inseguridad ciudadana, a partir del hecho de que las mismas se han caracterizado por la creación constante de nuevas figuras delictivas, la promulgación de leyes especiales y sobre todo, por la elevación de las penas privativas de libertad y del rigor en las condiciones de reclusión, que lejos de disminuir los niveles de la delincuencia, lo que han logrado es ampliar significativamente su grado de violencia y agresividad.

El expansionismo acelerado e irracional del derecho penal y las largas condenas de prisión, no siempre por violaciones demasiado graves de las normas de convivencia, agudiza el hacinamiento en las cárceles, hacinamiento que no parece importarles demasiado a los que diseñan y aplican la política criminal, especialmente en América Latina.

La vida de nuestros países no debe continuar dependiendo de la aprobación de leyes especiales, nuevas tipicidades delictivas, largas penas privativas de libertad, incremento del rigor penitenciario y sobre todo de la reducción de las garantías penales y procesales que con rango constitucional y afianzado en numerosos instrumentos jurídicos internacionales, constituyen los cimientos del Estado social y democrático de derecho.

En el siglo XXI en materia penitenciaria se aprecia una tendencia creciente a la ampliación de las sanciones y a la elevación de los requisitos para el otorgamiento de la libertad anticipada y otros beneficios penitenciarios; entre otros males, que afectan el régimen progresivo y el tratamiento penitenciario en general; en un entorno en el que los principios limitativos del derecho de castigar, han comenzado a ser observados de manera diferente desde la política, los instrumentos jurídicos internacionales y numerosas legislaciones nacionales.
Cuando se cumple la condena de un reo, se le abren las puertas de la cárcel para que reaprenda la vida en libertad, aunque este se topará con una sociedad de la que ha sido apartado por años y que cuenta con unas reglas de conducta distintas a las que vivió en prisión.

Por lo anterior, resulta iluso que al alcanzar la libertad, respete las leyes, cuando en prisión vivió con limitaciones y bajo el imperio de la "ley del más fuerte", por lo que para ser consecuentes con los resultados de nuestra investigación, estamos en el deber de reconocer el fracaso del tratamiento penitenciario, que redactado de forma atractiva en las leyes y reglamentos penitenciarios, en la realidad tiene un grado de cumplimiento mínimo.

\section{Referencias}

Asencio, H. (2006). Crisis de la pena privativa de libertad. En vigencia de las reglas mínimas de las Naciones Unidas para el tratamiento de los reclusos. Reforma Penal Internacional (RPI), Instituto Latinoamericano de Naciones Unidas para la Prevención del Delito y el Tratamiento del Delincuente (Ilanud). La Habana: Sociedad Cubana de Ciencias Penales.

Beck, U. (2002). La sociedad de riesgo global. Madrid: Siglo XXI Editores.

Berzosa, A. \& Martínez, C. (2002). Los efectos de la globalización y propuestas alternativas. Cuadernos de Derecho Judicial, V, pp. 131-152.

Blaustein, E. (2006). Prisiones privatizadas en EE.UU., modelo de exportación. Revista Zoom. Disponible en: http://revista-zoom. com.ar/articulo1324.html

Bonesana, C. (1993). Tratado de los delitos y las penas (12a ed.). São Pablo: Heliasta.

Carbonell, J.C. (2001). Reflexiones sobre el abuso del derecho penal y la banalización de la legalidad. En: M. Nieto (coord.). Homenaje al Dr. Marino Barbero Santos. In Memoriam, I (pp. 129-144). La 
Mancha: Ediciones de la Universidad de Castilla-La Mancha, Salamanca: Ediciones Universidad.

Carranza, E. (2012). Situación penitenciaria en América Latina y el Caribe. ¿Qué hacer? Anuario de Derechos Humanos. Disponible en: http://www.anuariocdh.uchile.cl/index. php/ADH/article/viewFile/20551/21723

Cervini, R. (s. f.) Sobre la desnaturalización dogmática de los atributos de la persona humana. Disponible en:http://www.fder. edu.uy/contenido/penal/cervini_desnaturalizacion-dogmatica-persona-humana.pdf

Christie, N. (1988). Los límites del dolor. México: Fondo de Cultura Económica.

De La Cruz, R. (2005). Intervención en el Seminario Internacional sobre Implementación de Penas Alternativas: Experiencias Comparadas de Cuba y Brasil. Convocado por Reforma Penal Internacional y Sociedad Cubana de Ciencias Penales, La Habana, 24 de febrero.

Galeano, E. (1996). El sacrificio de la justicia en los altares del orden. Conferencia pronunciada en el Auditorio de la Facultad de Derecho de la Universidad de Costa Rica, el día 21 de junio de 1996. Revista de la Asociación de Ciencias Penales de Costa Rica, 14. Disponible en: http://www. corteidh.or.cr/tablas/r17091.pdf

Goite, M. \& Medina, A. (2015). Migraciones, globalización, tráfico y trata de personas analizados desde una dimensión plural. En: A. Medina (coord.). Migraciones internacionales, tráfico y trata de seres humanos (pp. 6-67). La Habana: Editorial Unijuris.

Huertas, O., Bolívar, É., Sotelo, E., Camargo, E. \& López, É. (2015). Percepción, expectativas $y$ temores frente al regreso a la libertad en una muestra de reclusos colombianos en el año 2011. Revista Criminalidad, 57(2), pp. 221-233.

Jakobs, G. (2006). Derecho penal del ciudadano y derecho penal del enemigo. En: G. Jakob
\& M. Cancio. Derecho penal del enemigo (pp. 19-56). Navarra: Thomson-Civitas.

Jakobs, G. \& Cancio, M. (2003). Derecho penal del enemigo. Madrid: Civitas.

Javier, R. (2012). El Derecho penal del enemigo en la legislación relativa a los maras en EE.UU. y El Salvador. Revista Crítica Penal y Poder, 3, pp. 37-77. Disponible en: http://revistes.ub.edu/index.php/Critica PenalPoder/article/view/3480/6726

Lara, A. (2013). El conflicto social en la globalización neoliberal y el neoconservadurismo: entre las nuevas guerras y el populismo punitivo. Revista Crítica Penal y Poder, 4, pp. 132-148. Disponible en: http://revistes.ub.edu/index.php/CriticaPenalPoder/ article/download/5462/7549

López, J. (1997). El moderno derecho penal para una sociedad de riesgos. Revista del Poder Judicial, 48, pp. 289-322.

Mejías, C. A. (2014). La presunción de inocencia y los medios de comunicación masiva. Roma: Casa Editrice Dott. Antonio Milani.

Milanese, P. (s. f.). El moderno derecho penal y la quiebra del principio de intervención mínima. Disponible en: https:// www.unifr.ch/ddp1/derechopenal/ articulos/a_20080526_33.pdf

Mir Puig, S. (2003). Introducción a las bases del derecho penal. Montevideo: $\mathrm{B}$ de F.

Morillas, L. (2002). Reflexiones sobre el derecho penal del futuro. Revista Electrónica de Ciencia Penal y Criminología, 4. Disponible en: http://criminet.ugr.es/recpc/ recpc_04-06.html

Morillas, L. (2013). La función de la pena en el Estado social y democrático de derecho. Revista Internacional de Doctrina y Jurisprudencia, 4, pp. 1-26. Disponible en: http://www.ual.es/revistas/RevistaInternacionaldeDoctrinayJurisprudencia/pdfs/ 2013-12/articulos_discurso-investidura.pdf 
Morillas, L. (2014). La función de la pena en el Estado social y democrático de derecho. Revista Internacional de Doctrina y Jurisprudencia. Disponible en: http:// www.ual.es/revistas/RevistaInternacionaldeDoctrinayJurisprudencia/pdfs/2013-12/ articulos_discurso-investidura.pdf

Niño, L. (2015). El derecho penal como instrumento de exclusión. En: M. Goite. Globalización, delincuencia organizada, expansionismo penal y derecho penal económico en el siglo XXI. Libro Homenaje al Prof. Dr. Juan María Terradillos Basoco (pp. 89-122). La Habana: Editorial Unijuris. Disponible en: http://www.lex. uh.cu/node/44

Olivares, G. (1992). Derecho penal. Parte general. Reedición de la segunda edición. Madrid: Editorial Marcial Pons.

Olvera, R. (2013). La expansión penal como política criminal del código penal para el distrito federal. Biblioteca virtual de la Universidad Nacional Autónoma de México. Disponible en: http://biblio.juridicas. unam.mx/libros/7/3390/2.pdf

Pavarini, M. (1986). Fuera de los muros de la cárcel: la dislocación de la obsesión correccional. Barcelona: PPU.

Pisarello, G. (2001). Globalización, constitucionalismo y derecho. En: M. Carbonell y A. Vázquez (comps.). Estado constitucional y globalización (pp. 248-249). México: Porrúa.

Portilla, G. (2005). Los excesos del formalismo jurídico neofuncionalista en el normativismo del Derecho penal. En: G. Portilla (coord.). Mutaciones del Leviatán, legitimación de los nuevos modelos penales (pp. $241 \mathrm{y}$ ss). Madrid: Universidad Internacional de Andalucía.

Programa de las Naciones Unidas para el Desarrollo (PNUD), Informe Sobre Desarrollo Humano. (2013). El ascenso del sur: progreso humano en un mundo diverso, UN Plaza, Nueva York, NY 10017, Estados Unidos. Disponible en: http://www. undp.org/content/dam/undp/library/corporate/HDR/2013GlobalHDR/Spanish/ HDR2013\%20Report\%20Spanish.pdf

Rivero, J. (s. f.). El derecho penal del enemigo: ¿Derecho penal de la globalización? Disponible en: http://www.derecho.uady.mx/ tohil/rev25/derechopenal.pdf

Rodríguez, J. (2014). El fracaso de la pena privativa de libertad. Disponible en: http://www.incipp.org.pe/media/uploads/ documentos/j.rodriguez-penaprivativa1. pdf

Sanz, N. (2012). De las libertades del marqués de Beccaria al todo vale de Günther Jakobs. El fantasma del enemigo en la legislación penal española. Revista Electrónica de Ciencia Penal y Criminología, 14. Disponible en: http://criminet.ugr.es/recpc/14/ recpc14-10.pdf

Silva, J. (1999). La expansión del derecho penal. Aspectos de la política criminal en las sociedades posindustriales. Madrid: Civitas.

Terradillos, J. (2001). Sistema penal y criminalidad internacional. En: M. Nieto (coord.). Homenaje al Dr. Marino Barbero Santos. In Memoriam, I, (pp. 749-778). La Mancha: Ediciones de la Universidad de Castilla-La Mancha, Salamanca: Ediciones Universidad.

Velásquez, F. (s. f.). Globalización y derecho penal. Bogotá: Universidad Sergio Arboleda. Disponible en: https://www.unifr.ch/ddp1/ derechopenal/articulos/a_20080527_34. pdf

Zaffaroni, E. R. (1998). En busca de las penas perdidas. Deslegitimación y dogmática jurídico-penal. Buenos Aires: Ediar.

Zaffaroni, E., Alagia, E. \& Slokar, A. (2006). Manual de derecho penal. Parte General. Buenos Aires: Editorial Ediar. 
Zaffaroni, E. R. (2011). ¿Es posible una contribución penal eficaz a la prevención de los crímenes contra la humanidad? Revista de la Asociación Americana de Juristas, pp. 7-36. Buenos Aires: Ediciones del País.
Zaffaroni, E. (2015). Violencia letal en América Latina. Cuadernos de Derecho Penal, enero-junio, pp. 57-75. Disponible en: http://revistas.usergioarboleda.edu.co/index.php/cuadernos_de_derecho_penal/ article/download/455/385 